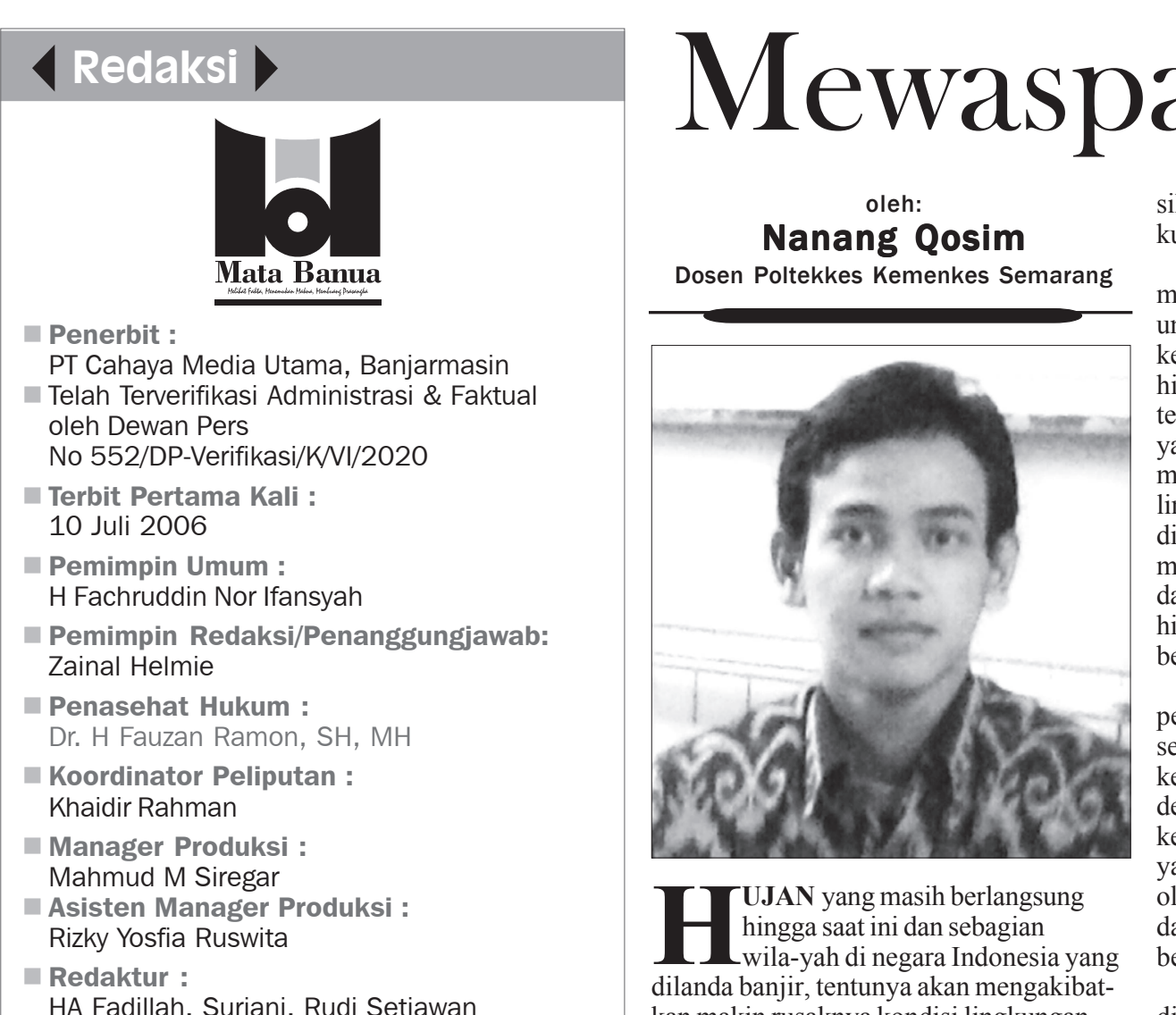

\section{Staf Redaks : \\ Bambang Santoso, lin
Dwiki Hamza Nugrah \\ Biro-Biro/Perwakilan :
Rizal Fachrani (Jakarta) \\ (Tapin), Muhammad Yusuf (Hulu Sunga \\ Kabupaten Banjar), (Balangan) \\ Ebet Hadiani (Kotabaru) Risma (Tanah
Laut), Akhmad Alfiannor (Tanah Bumbu) \\ Lay Out :
Akhmad Riza, Ronny Friandy, Amril Sofyan, \\ Taufiqqurahman}

Produksi Iklan / IT Web :
Pahliawan Patria

Ibnu Zulkarnain

Pemimpin Perusahaan :

Sekretaris Perusahaan :

\section{Manager Iklan
Hj Noor Diana \\ Alamat Redaksi/Bisnis/Sirkulas : \\ Jl Lingkar Dalam Selatan Banjarm}

- e-Mail : redaksi_matabanua@yahoo.com

e-Mail Iklan : iklan.matabanua@yahoo.

Harga Langganan : Rp 75.000/bulan
dalam kota

PT Grafika Wangi Kalimantan
Isi Diluar Tanggung-jawab Percetakan

Tarif Iklan :

$\begin{array}{ll}\text { DISPLAY UMUM : } & \\ \text { Hitam Puth (BW) } & \text { : Rp } 8.000 / \mathrm{mmk}\end{array}$

$\begin{array}{ll}\text { Spot Colour (SC) } & : \mathrm{Rp} 10.000 / \mathrm{mmk} \\ \text { Full Colour (FC) } & : \mathrm{Rp} 15.000 / \mathrm{mm}\end{array}$

$\begin{array}{ll}\text { DISPLAY HALAMAN MUKA : } \\ \text { Hitam Putih (BW) } & : \text { Rp 13.000/mmk } \\ \text { Spot Colour (SC) } & \text { Rp 15.000/mmk } \\ \text { Full Colour (FC) } & : \text { Rp 24.000/mmk }\end{array}$

Full Colour (FC) : Rp 24.000/mk
DISPLAY HALAMAN BELAKANG:
Hitam Putih (BW) : Rp 10.000/mmk

$\begin{array}{ll}\text { Hitam Putih (BW) } & : R p ~ 10.000 / m m \\ \text { Spot Colour (SC) } & : R p 13.000 / m m k \\ \text { Full Colour (FC) } & : R p ~ 22.000 / m m k\end{array}$

IKLAN KOLOM
IKLAN KELUARGA

IKLAN BARIS

Rp 5.000/ mmk
$\operatorname{Rp} 5.000 / \mathrm{mmk}$

Catatan:

\section{口 TELEPON PENTING}

Polda Kalsel

Poltabes Banjarmasin

Polsek Banjar Tengah

Polsek Banjar Barat

Polsek Banjar Timur

Polsek Banjar Selatan

Polsek Banjar Utara

KPPP Poltabes Banjarmasin

Polres Banjar

Polresta Banjarbaru

RSUD Ulin

RS Ansyari Saleh

RS Suaka Insan

RSIslam

RS DR Soeharsono

RS Siaga

RS Sari Mulia

RSUD Banjarbaru

PMK Hippindo

Rescue 911

336857

3251411

3353003

4412952

3252473

3261244

3300463

3368305

4721110

2772266

3257472

3300741

3352225

335489

3368422

3253111

3252570

4772380

7500911

9110911

REDAKSI menerima sumbangan tulisan opini, artikel maupun surat pembaca lainnya. Panjang tulisan opini/artikel
maksimal 3 (tiga) halaman kuarto, dike maksimal 3 (tiga) halaman kuarto, dike maksimal 1 (satu) halamankuarto Sem isi tulisan opini dan artikel bukan mencerminkan sikap redaksi dan

merupakan tanggungjawab penulisnya.

Redaksi berhak mengedit tulisan sepanja

tidak mengubah esensi yang ada. Semua

diri yang masih berlaku, dikirim Alamat

Redaksi/Bisnis/Sirkulasi:Jl Pekapuran

Rt 32 No 87 JI Lingkar Dalam Selatan

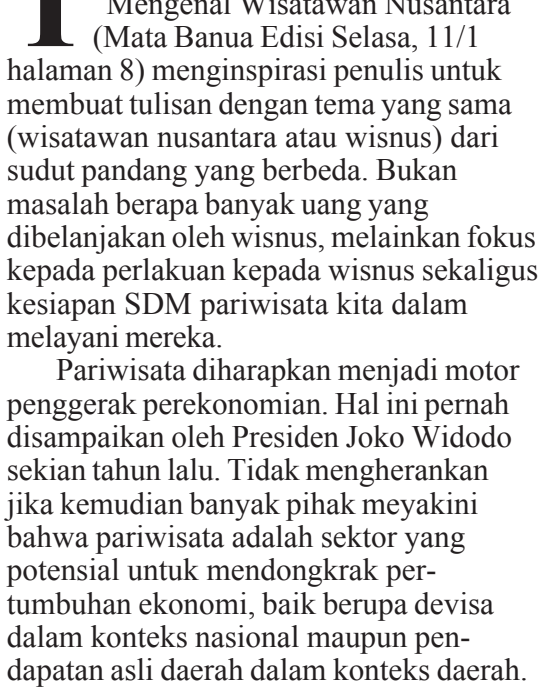

H. Ahdiat Gazali Rahman

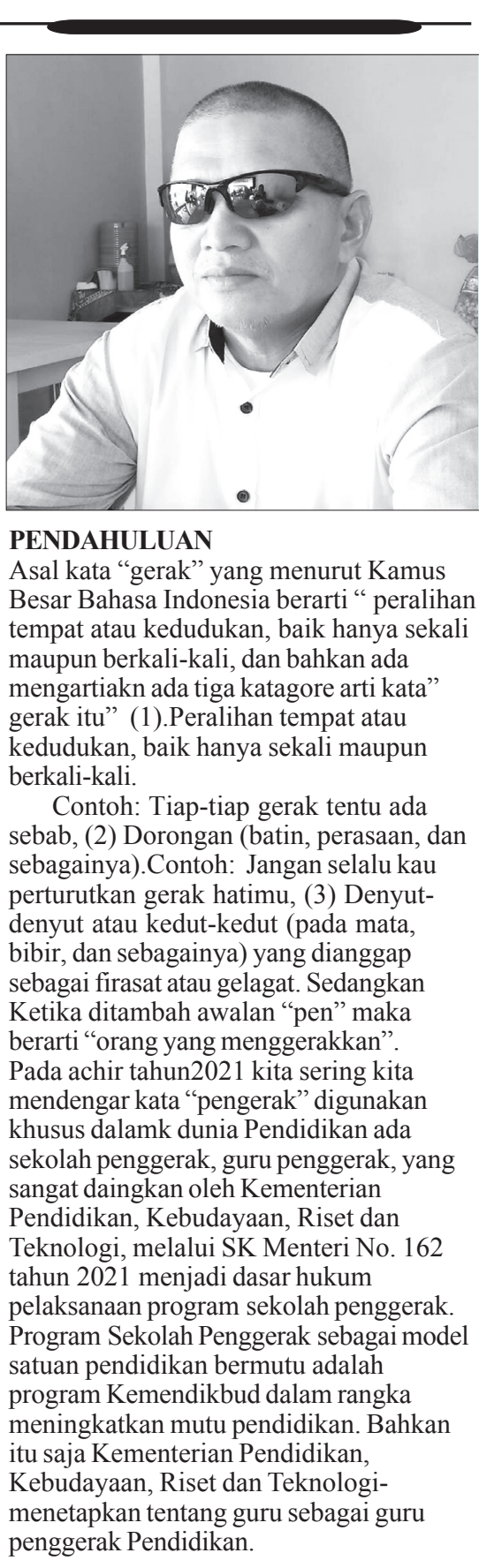

\title{
Mewaspadai Penyakit Lingkungan
}

Hal itu juga bisa menimbulkan berbagai
masalah kesehatan, salah satunya
menyangkut tingginya kasus penyakit
berbasis lingkungan.
Penyakit berbasis lingkungan masih
merupakan penyebab utama kematian di
Indonesia. Bahkan, pada kelompok bayi
dan balita, penyakit-penyakit berbasis
lingkungan telah menyumbangkan lebih
80\% dari penyakit yyang diderita oleh bayi
dan balita. Keadaan tersebut mengindika-

Wisatawan Nusantara: Anak Tiri di Negeri Sendiri?

Eko Sugiarto

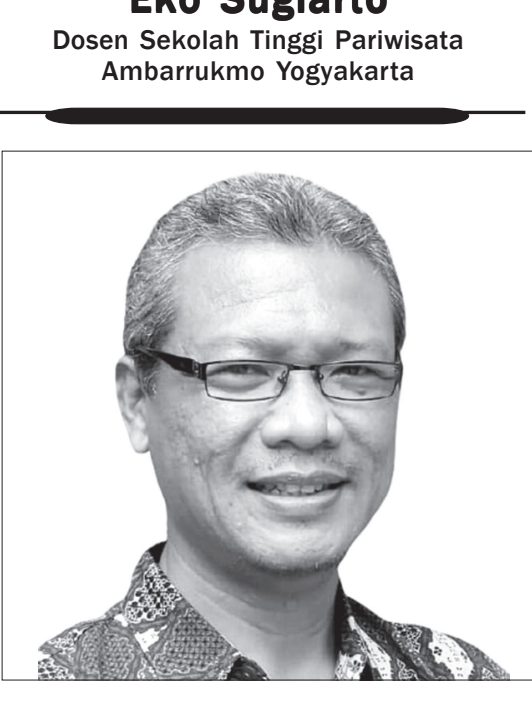

T

ualitas intervensiani kesehatan lingku

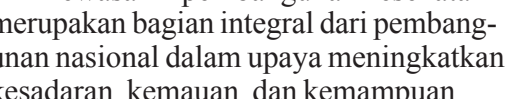

embangun kesehat-an dan wawasan

imbangi dengan intervensi perilaku y
memungkinkan masyarakat tebih menna-
ari, mau, dan mampu untuk melakuka

Munbagai pencemaran dan pengrusakak
Muncunna kembali beberapa

makin besarnya tekanana bahaya

作

penanganan sampah serta limbal
Teori Henunhir syarat kesehatan.
T. Bloom telah jel

terhadap terciptanya peningkatan derajat
kesehatanan seseorang berasal dari kualitas
kesehatan lingkungan dibandingkan fakto
yang lain. Bahkan, lebih jauh ada korelas

yang lain. Bahkan, lebih jauh ada korel
yang cukup bermakna antara kualitas

esehatan lingkungan dengan kejadian

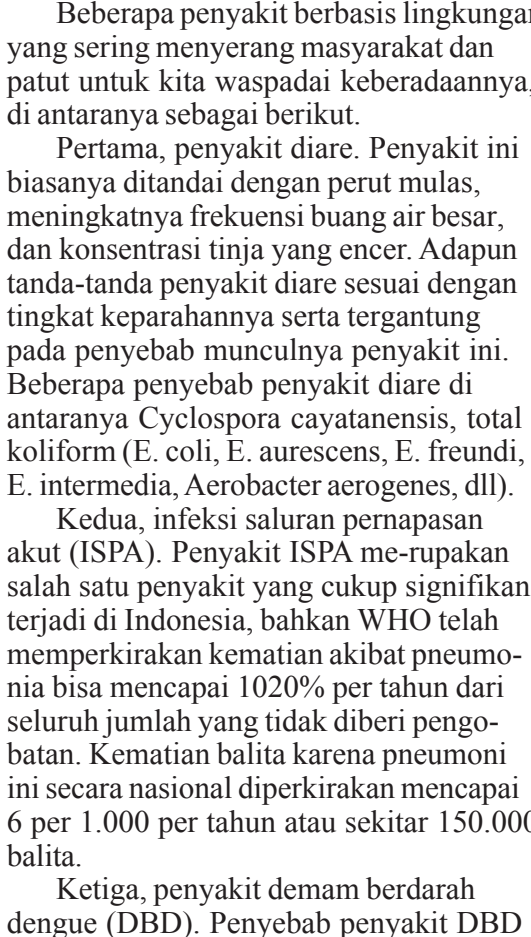

erupakan penyakit batuk berdahak lebih

ni adalah kuman atau bakteri Micobacteri-

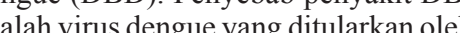

berkembang biak dapat di dalam maupu

tempat yang dapat menampung air be

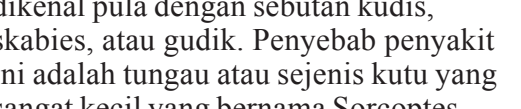

scabies. Tungau ini berkembang biak
sates

kulit kita dan membuat terowongan
dibawah kulit sambil bertelur. Cara
Denularan penyakit ini dengan cara

kontak langsung dan melalui peralatan,
seperti baju, handuk, seprai, bantal, da

fektif untuk menghindari penyakitin ini
yaitu dengan menggunakan air bersih dan

Tingginya angka kejadian penyakit
berbasis lingkungan, sangat erat kaitanny

epada masyarakat. Untuk itu, pening-

mendapatkan perratian khusus. Untuk

$\begin{array}{cc}\text { eperti kamar mandi, pot bunga, tempat } & \text { bersih dan sehat) dan upaya penyehatan } \\ \text { ninum burung, dan lain sebagainya. } & \text { lingkngan, diharapkan bisa menjadi } \\ \text { Keempat, penyakit malaria. Penyakit } & \text { upaya alternatif dalam mengendalikan d }\end{array}$

erbasis lingkungan yang sering menye-

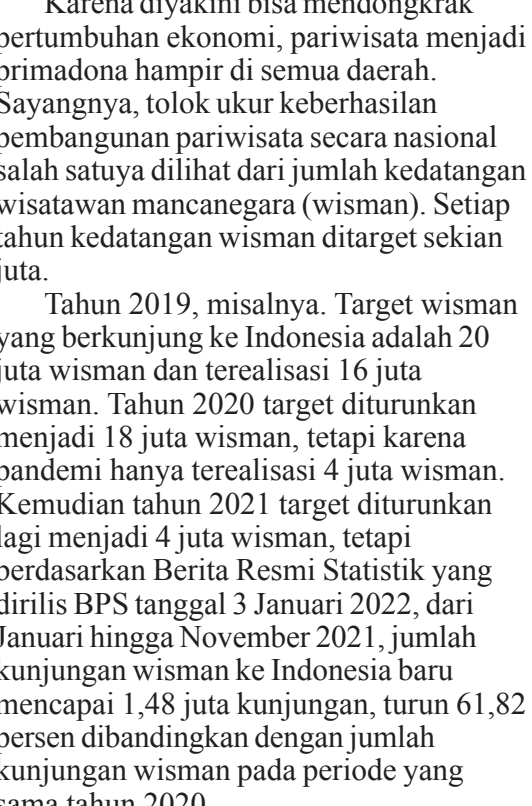

Sekolah Penggerak Sebuah Harapan?
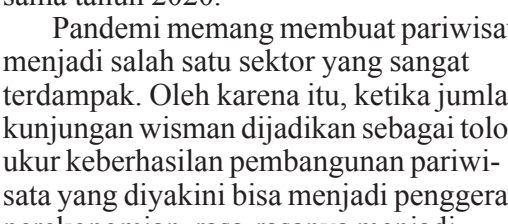

perekonomian, rasa-rasanya menjadi
kurang masuk akal. Ketika pandemi

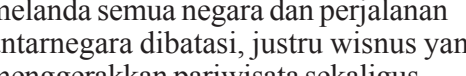

Wisnus sebagai penggerak sektor
pariwisata sekaligus ekonomi juga diaku
oleh Menteri Parekraf. Dalam diskusi

ortema "Kolaborasis Perguruan Tingg
Industri Dalam Pengembangan Produk

ariwisata yang Kreatif dan Inovair
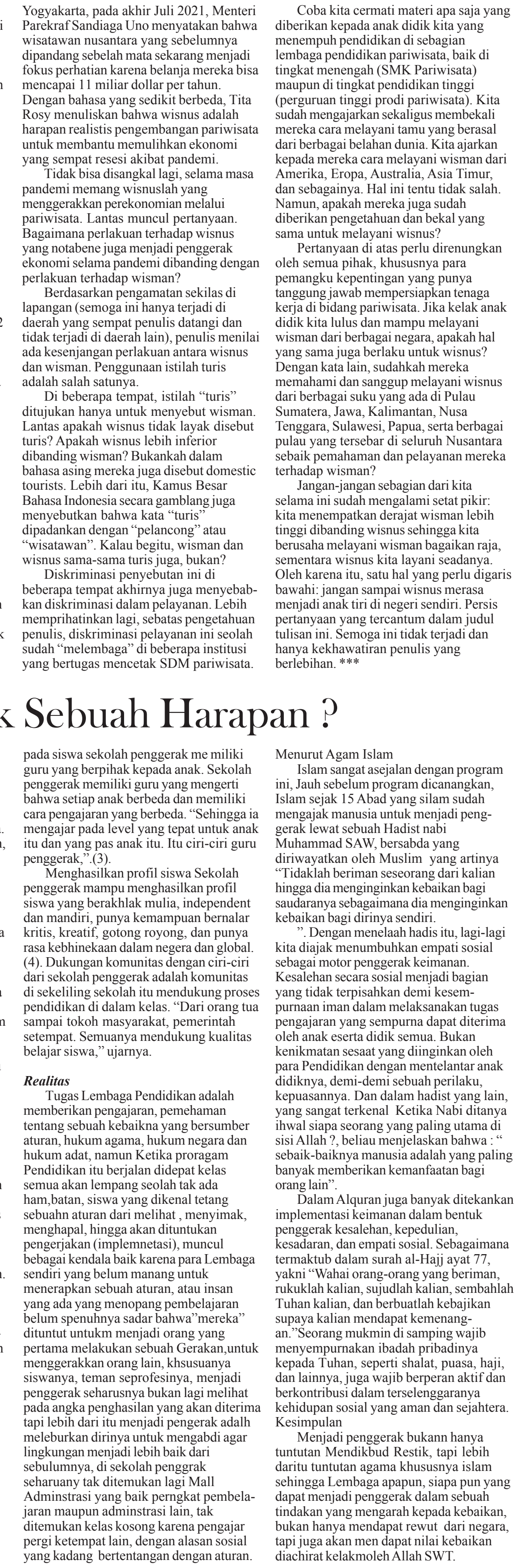